\title{
EVALUATION OF SEALING ABILITY OF AH PLUS AND tg ROOT CANAL SEALERS IN THE PRESENCE AND ABSENCE OF SMEAR LAYER
}

\author{
Tahir Ali Khan ${ }^{1}$, Nighat Shafique ${ }^{1}$, Mumtaz-UI-Islam ${ }^{1}$, Raham Zaman ${ }^{1}$ \\ 1. Sardar Begum Dental College
}

\begin{abstract}
Background:

Smear layer is considered to be the main contributing factor in better sealing and adhesion of a sealer.

Objective:

The aim of this study is to determine the sealing ability of two root canal sealers (AH Plus and tg). In the presence and absence of smear layer

\section{Methodology:}

Extracted teeth from patients visiting Sardar Begum Dental College 60 in numbers were used in this study. Specimens were divided in to two main groups (group1 and group 2) both groups were instrumented using a step back technique. Irrigation was done during instrumentation with one $\mathrm{ml}$ of $5.25 \% \mathrm{NaOCl}$ solution. In group2 a final flush with $10 \mathrm{ml}$ of $17 \%$ EDTA solution followed by $10 \mathrm{ml}$ of $5.25 \% \mathrm{NaOCl}$ was used for smear layer removal. Each group then further divided in to two sub groups $(n=15)$. After obturation specimens were kept in separate containers with wet gauze to maintain 100\% humidity. The specimens were coated with nail polish except for apical $2 \mathrm{~mm}$. Specimens were then suspended vertically in two \% methylene blue dye for 7 days. Longitudinal sectioning was done to determine the extent of dye penetration using a stereo microscope at X30 magnification. Student $t$ test was used for statistical analysis $(p \leq 0.05)$.
\end{abstract}

\section{Results:}

The results showed that in the presence of smear layer, mean apical dye leakage of AH Plus was2.89 $\mathrm{mm}$ and tg was $4.02 \mathrm{~mm}$. While in the absence of smear layer the mean dye leakage of AH Plus was $2.23 \mathrm{~mm}$ and tg was $3.28 \mathrm{~mm}$. Student $t$ test was more than $p$ value indicating non significant result for both sealers.

\section{Conclusion:}

Apical sealing ability of AH Plus is better than tg root canal sealer in the presence and absence of smear layer.

\section{Keywords:}

Sealer, Smear layer Sealing Ability, Root Canal Sealers, Microleakage.

\section{INTRODUCTION}

Failure in the root canal treatment is mainly due to microleakge ${ }^{1}$. A three-dimensional seal of root

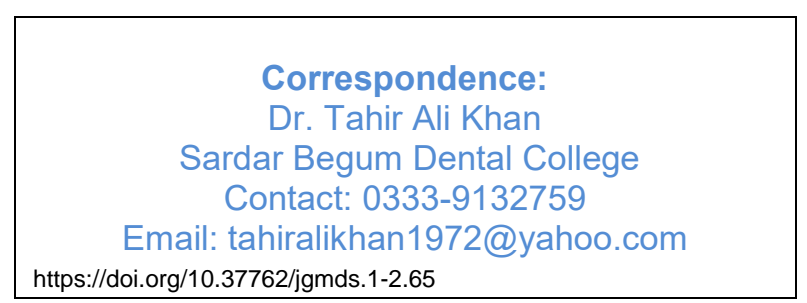
canal system to prevent micro leakage of bacteria and their by-products is an important phase in achieving good prognosis for endodontic treatments. A fluid tight seal for the entire root canal system to minimize failure rates is mendatory ${ }^{2}$. The leakage through a filled root canal occurs at the between the sealer and dentin interface or the sealer and gutta percha interface, or through voids within the sealer. Therefore, the sealing quality of a root canal filling depends on the sealing ability of the sealer used ${ }^{3}$. In endodontics the smear layer is described as the debris produced iatrogenically by the cutting of dentin of the root canal walls Smear layer can be observed only with scanning electron microscope which is composed of two confluent elements ${ }^{4,5}$. 
A superficial thin layer of smeared material on the surface of root canal wall of 1-2 micrometer in thickness and a deep layer which is packed into some of the dentinal tubules extending a distance of up to 40 micrometer $^{6}$. The presence of smear layer has received considerable attention. Some researchers recommend the removal of smear layer while others insist on an intact smear layer. According to Sharavan et al that smear-free obturated canals leaked significantly less than groups with intact smear layer ${ }^{7}$. Galvin et al had shown that the presence of smear layer resulted in reduced apical leakage as compared to those without smear layer ${ }^{8}$. Evans and Simon (1986) concluded that the presence or absence of smear layer has no significant effect on the apical seal ${ }^{9}$.

Controversies still exists over the effect of smear layer on the apical sealing ability of various root canals sealers. Not much literature is available locally. There is no one solution for different situations. More Research is required for bridging the gaps in knowledge regarding the presence or absence of smear layers when two different sealers are compared to each other. Hence, the purpose of this study is to determine the effect of presence or absence of smear layers on microleakage when two sealers. AH Plus most widely used conventional nonbonding epoxy resinbased sealer of first generation containing non-acidic diurethane dimethacrylate and triethyleneglycol dimethacrylate ${ }^{10}$. The other one was the most convenient sealer tg containing zinc oxide eugenol, were used. Hypothesis of the study was there is no difference in sealing ability of either sealer by the presence or removal of the smear layer.

\section{METHODOLOGY}

In this in vitro experimental study extracted teeth obtained from patients visiting the department of oral and maxillofacial surgery, Sardar Begum Dental College, Gandhara University, Peshawar, KPK, Pakistan. Patients were advised by oral diagnosis department for extraction and a few were extracting teeth by their on will due to time and other restrictions. Selections of the teeth were based on:

1. Single rooted teeth

2. The roots will have no fractures, caries and/ or open or resorbed apices

3. All root roots will be straight or will have slight curvature (5-10 degrees)

Teeth with pulp stones and internal resorption were excluded from the study.

Preparation Of Specimens: This study was performed on 60 extracted human teeth which fulfilled the inclusion and exclusion criteria. In order to have clean surfaces, all the teeth were placed in $2.5 \% \mathrm{NaOCl}$ solution for 48 hours. The teeth were radio graphically investigated to ensure that they have single canals and that there were no calcifications. To standardize the teeth, the crowns of the teeth were cut at cemento-enamel junction using a diamond disk so that an average length of the remaining roots was approximately $13-15 \mathrm{~mm}$.

Cleaning And Shaping Of Specimens: All teeth were kept in normal saline solution during the experiment. The pulp tissue from the root was extirpated with a nerve broach. A \#15 reamer (Mani, Japan) and rubber stop was used to determine the working length for each root. All roots were instrumented up to a \#40 K-file, and the coronal part was flared up to \#60 K-file using step back technique. A \#10 reamer was used to ensure apical patency between each file. During instrumentation $5.25 \% \mathrm{NaOCl}$ was used as irrigant for all specimens.

Grouping Of Specimens: After completion of the instrumentation, the specimens were divided into Group1 (specimens with smear layer) and Group 2 (specimens with no smear layer), thirty specimens in each group. Group 1 specimens were irrigated with a final flush of $5.25 \% \mathrm{NaOCl}$ solution after instrumentation to keep the smear layer intact. While the Group 2 specimens were irrigated with a final flush of $10 \mathrm{ml}$ of $17 \%$ EDTA solution and followed by $10 \mathrm{ml}$ of $5.25 \% \mathrm{NaOCl}$ solution after instrumentation to remove the smear layer. The specimens were divided into two sub groups as A1 and A2 ( $\mathrm{AH}$ Plus sub-groups) and B1and B2 (tg sub-groups), each sub-group consists 15 specimens. 
Obturation After completion of the final irrigation phase, all the specimens in sub-groups were dried with paper points and then were obturated with lateral condensation technique using \# 40 gutta percha as master cone and \#25 gutta percha as accessory cones. The sealers were mixed according to manufacturer recommendations.

Coronal Restorations: The coronal $3 \mathrm{~mm}$ of the specimens in all sub-groups were sealed with Cavit temporary filling.

Incubation: To ensure setting of the sealer in the experimental groups, the samples were kept in $100 \%$ humidity with $37^{\circ} \mathrm{C}$ temperature for 7 days.

Coating With Nail Polish: Each specimen was blotted dry and coated twice with nail polish except for the apical $2 \mathrm{~mm}$ which was covered with sticky wax.

Suspension of Specimens In Dye: The specimens were then suspended upright in airtight containers containing $10 \mathrm{ml}$ of $2 \%$ solution of Methylene blue and were kept in an incubator at $37^{\circ} \mathrm{C}$ for one week.

After removing the samples from the incubator, they were thoroughly washed with water and the nail polish and sticky wax were removed from the surfaces.

Sectioning Of Specimens The roots were then grooved labially and lingually with a diamond disc with intermittent cutting under water spray without involving the root canal. Using a spatula the roots were separated into two parts and the gutta-percha and filling material was removed from the canals.

Measurements Of Microleakage: Both the root sections of each specimen were viewed under a stereomicroscope with X30 magnification. Linear measurements of the most coronal extent of dye penetration on the canal walls were recorded in $\mathrm{mm}$ up to two decimals.

The SPSS version 16 was used to analyze the collected data. Both the groups were compared using paired sample $t$ test. $p$ value of less than 0.05 was considered as significant.

\section{RESULTS}

Gross Examination: Leakage of the methylene blue dye was observed in all the specimens except two specimens (Table1). The leakage occurs mostly at the sealer-dentine interface. Some amount of the dye leakage was also seen at the sealer-gutta percha interface and also through the sealer. Leakage Values: Group 1: In A1 sub group (AH plus with smear layer) the leakage values ranged from $0.00 \mathrm{~mm}$ to $4.84 \mathrm{~mm}$ with the mean value $2.89 \mathrm{~mm}$ and standard deviation of $1.55 \mathrm{~mm}$ (Table2). In B1 sub group (tg with smear layer) the leakage values ranged from $1.10 \mathrm{~mm}$ to $8.57 \mathrm{~mm}$ with the mean value $4.02 \mathrm{~mm}$ and standard deviation of $2.65 \mathrm{~mm}$ (Table2). Group 2: In A2 sub group (AH plus without smear layer) the leakage values ranged from $0.79 \mathrm{~mm}$ to $3.60 \mathrm{~mm}$ with the mean value $2.23 \mathrm{~mm}$ and standard deviation of $0.82 \mathrm{~mm}$ (Table2). In B2 sub group (tg without smear layer) the leakage values ranged from $0.00 \mathrm{~mm}$ to $8.21 \mathrm{~mm}$ with the mean value $3.28 \mathrm{~mm}$ and standard deviation of $2.20 \mathrm{~mm}$ (Table2). Mean values with and without smear layer of both sealers on the basis of their sealing ability provides different values (Figure1). Mean values for AH Plus with smear layer was much lower than tg (Figure3) with intact smear layer and when paired T-test was applied, it was no significant because of the value obtained 0.132 with 2 tailed significance. When $T$ test was applied for AH Plus without smear layer and tg without smear layer (Figure3) it provided a value of 0.124 which is greater than 0.05 indicating a non significant difference when calculated statistically for two tailed test. When paired T test was applied for AH Plus with smear layer and without smear layer a mean value for both is 0.66 and two tailed significance was 0.69 which is greater than $p$ value it was a non significant result (Figure2). All the tests provided greater than the values of $p$ which was 0.05 so it confirmed that there is no difference when sealers were applied with smear layer and without smear layer. It also indicated that no sealer is able to seal completely and effectively when used with and without smear layer.

Table-1. Extent of dye penetration in $\mathrm{mm}$ noted for leakage values of all specimens. 


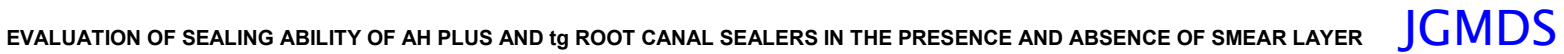

\begin{tabular}{|c|c|c|c|}
\hline $\begin{array}{c}\text { AH Plus } \\
\text { with smear } \\
\text { layer }\end{array}$ & $\begin{array}{c}\text { tg with smear } \\
\text { layer }\end{array}$ & $\begin{array}{c}\text { AH Plus without } \\
\text { smear layer }\end{array}$ & $\begin{array}{c}\text { tg without } \\
\text { smear layer }\end{array}$ \\
\hline 2.50 & 2.30 & 2.15 & 5.60 \\
\hline 2.50 & 1.10 & 2.89 & 2.86 \\
\hline 0.00 & 1.30 & 0.99 & 2.84 \\
\hline 0.80 & 2.75 & 2.07 & 8.21 \\
\hline 1.00 & 5.90 & 2.00 & 2.37 \\
\hline 1.40 & 7.30 & 2.34 & 1.71 \\
\hline 2.70 & 1.70 & 2.27 & 0.00 \\
\hline 2.98 & 2.10 & 1.24 & 1.50 \\
\hline 3.20 & 8.57 & 0.79 & 5.40 \\
\hline 3.50 & 1.35 & 2.10 & 6.66 \\
\hline 4.34 & 2.90 & 1.99 & 1.70 \\
\hline 4.50 & 6.60 & 2.50 & 2.44 \\
\hline 4.56 & 3.00 & 3.26 & 2.78 \\
\hline 4.64 & 8.05 & 3.60 & 2.24 \\
\hline 4.84 & 5.40 & 3.34 & 2.98 \\
\hline
\end{tabular}

Table-2. Minimum, maximum and mean leakage values in $\mathrm{mm}$ with standard deviation.

\begin{tabular}{|l|c|c|c|c|}
\hline & $\begin{array}{c}\text { AH Plus With } \\
\text { Smear Layer }\end{array}$ & $\begin{array}{c}\text { tg with } \\
\text { Smear Layer }\end{array}$ & $\begin{array}{c}\text { AH plus } \\
\text { Without Smear } \\
\text { Layer }\end{array}$ & $\begin{array}{c}\text { Tg without } \\
\text { Smear Layer }\end{array}$ \\
\hline No. Valid & 15 & 15 & 15 & 15 \\
Missing & 0 & 0 & 0 & 0 \\
Mean & 2.8973 & 4.0213 & 2.2353 & 3.2860 \\
Std. Deviation & 1.55096 & 2.65633 & .82125 & 2.20096 \\
Minimum & .00 & 1.10 & .79 & .00 \\
Maximum & 4.84 & 8.57 & 3.60 & 8.21 \\
\hline
\end{tabular}

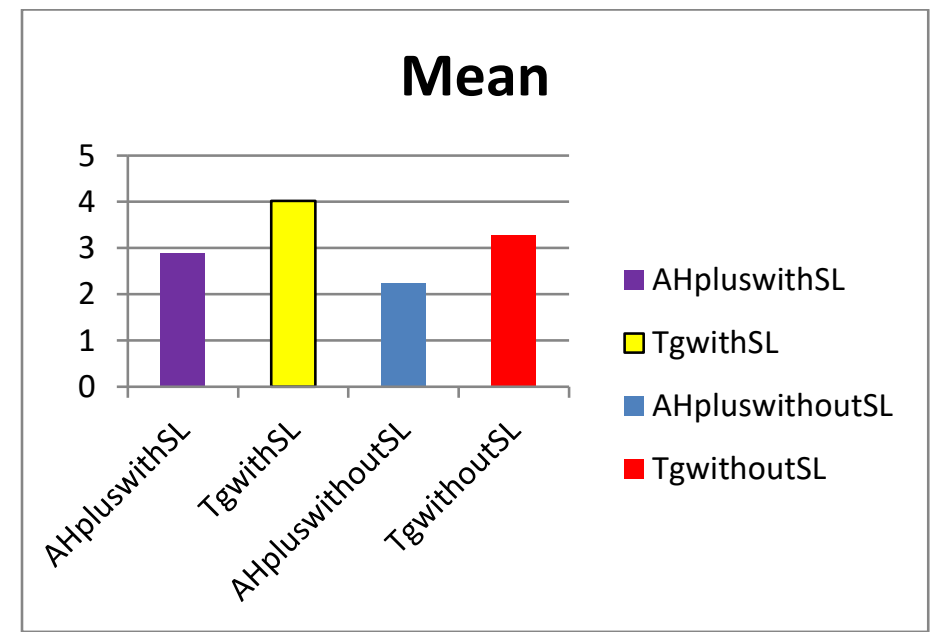

Figure 1: Mean values of leakage in millimeters 


\section{comparison of $T$ test values with $p$ value}

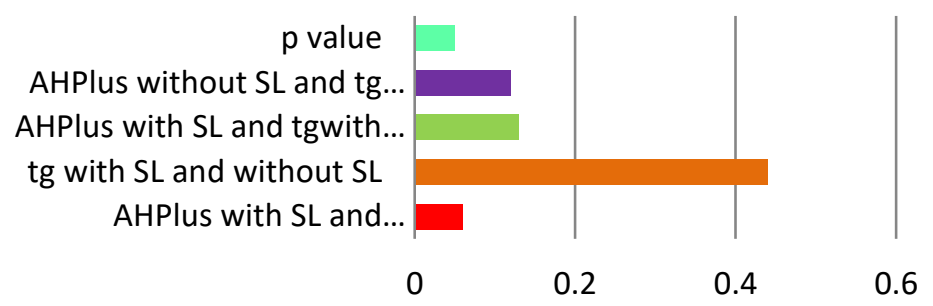

AHPlus with SL and without SL

tg with SL and without SL

AHPlus with SL and tgwith SL

Figure 2: Comparisons of $\mathrm{T}$ test with $\mathrm{p}$ value in a graphical order

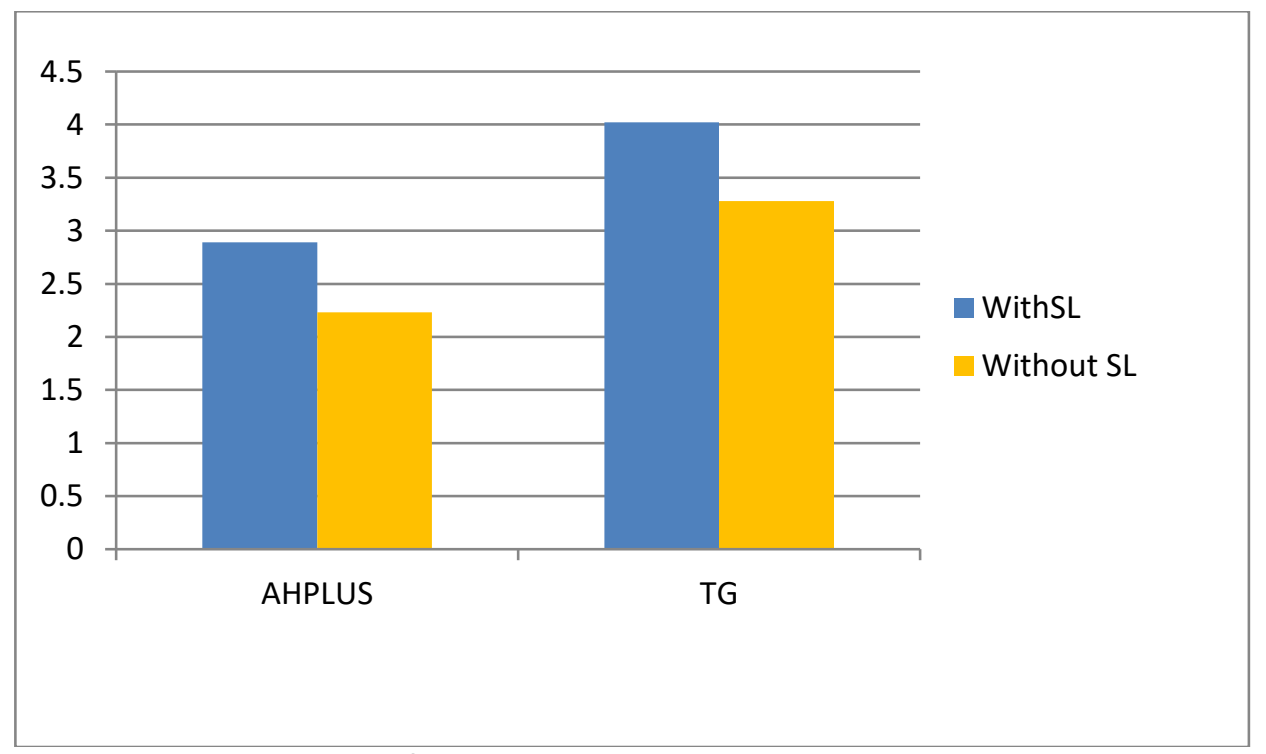

Figure 3: Mean values for ah plus and tg with and without smear layer.

\section{DISCUSSION}

Root canal filling techniques and the obturating materials can be assessed clinically but such investigations require long observation periods to be meaningful. These studies are often difficult to complete due to dropping out of enrolled subjects. Clinical investigations are also difficult to standardise and the results may vary due to differences in the skills of the operators as well as differences in the criteria used for evaluation of the results. Therefore, various in vitro techniques have been introduced to evaluate the ability of different obturation techniques and obturating materials to obtain an adequate apical seal. In vitro techniques to evaluate obturating materials are based on the assessment of micro leakage along the obturated root canals (Al-Ghamidi and Wennberg 1994) ${ }^{11}$ including bacterial penetration (Goldman et al. 1989 ${ }^{12}$, Goldberg et al. 1985 ${ }^{12}$ ), dye penetration (Evans and Simon 1986) ${ }^{9}$, isotope penetration (Matloff et al 1982) ${ }^{14}$ and scanning electron microscopy, electrochemical techniques (Jacobson and von fraunhofer 1976) ${ }^{15}$, 
flourometry (Ainley 1970) ${ }^{16}$, staining technique (Hovland and Dumsha 1985) ${ }^{17}$ and liquid pressure technique (Wu et al. 1993) ${ }^{18}$.

Among these techniques, dye Penetration is the method most widely used (due to its simplicity) to evaluate the apical seal of root canals. It is important to remember that the results of the dye penetration studies indicate only the relative sealing ability of root Canal fillings in Vitro, and they do not indicate their ability to prevent the penetration of bacteria into filled roots and in vivo. Stereo microscope examination of the sectioned specimens showed that leakage occurred through apical foramen, between the sealer and the root canal wall, between the gutta percha and sealer and also through the sealer. Absorption of the dye in the sealers may also represent cohesive failure in the body of the sealer, creating another pathway for the leakage. This study supports the findings of other investigations that all root canals fillings leak (Limkangwalmongkal et al. $1991^{19}$, Gee et al. $1994^{20}$ ). An ideal $100 \%$ hermetic seal of canals occur rarely (Osins et al. 1983) ${ }^{21}$. The variations in the leakage values for the individual specimens in all groups could be attributed to any entrapement of air in those specimens where leakage was minimal (Goldman et al. 1989). Dye penetration in the presence of smear layer which provided that AH Plus was more effective in the sealing ability than the $\operatorname{tg}$ sealer is in accordance with previous studies (Al-Ghamidi and Wennberg 1994). In the present study, the mean leakage value of tg sealer was more than AH Plus which was affirmative with other studies (Gambarini and Tagger, 1996). Zinc oxide based sealers were considered as basic type of sealers and still used for comparative studies for new materials (Schuurs et al 1993) ${ }^{22}$. Smear layer blocks and make it difficult for a sealer to make an access and bond with the dentine. When the smear layer removed it is generally accepted that a better bond and sealing was achieved. Both the materials showed a better sealing ability without the smear layer removal which is affirmative with previous study ${ }^{23}$. On the basis of mean leakage values from the present study AH Plus was found best as compared to the tg sealer which is in accordance with other studies ${ }^{24}$.

Promising results were also found from other study which was conducted on sealing ability of sealers (AH Plus and Roeko Seal) on coronal and apical area for the effects of smear layer ${ }^{25}$. Results with treated smear layer are in accordance with this study where sealing was found effective when smear layer was removed ${ }^{26}$. As apical sealing ability was the aim of the current study so the crown portion of the teeth was of no value. Teeth were decoronated to facilitate for an easy access and manipulation to follow the methodology of previous studies ${ }^{27,28}$. Adhesion of sealing agents when compared for positive smear layer specimens and negative smear layer specimens provided confirmatory results when compared for adhesion to the surface of canals confirmed the results of present study ${ }^{29}$. Sealing ability of sealers without smear layer also provided promising results with this study ${ }^{30}$. Zinc oxide based sealers were proved to be of the least effective sealing capability which was confirmed with other studies because these sealers have no chemical adhesion to the dentinal tissues which was affirmative through this study ${ }^{31}$. Resin based sealers are of great value in terms of sealing ability as they act through resin tag formation with the conditioned dentine from where smear layer was removed Pameijer and Zamener in $2010^{32}$. The resin containing sealer provides maximum resistance in comparisons with zinc oxide sealer to dye penetration which confirms its sealing ability better than zinc oxide containing sealer. Same results were present in the current study. An affirmative result with the previous studies observed through this research.

\section{LIMITATIONS OF THE STUDY}

Large scale research needed to detect even a minor difference which is not possible through this short duration of time. A large sample size also needed for detection of real situation which is not possible in this in vitro study due to non availability of any funding agency. Results of the study were implicated on in vivo conditions which though practiced yet needed great considerations. Recommendations for in vivo studies are supported to generalize exactly the results. 


\section{CONCLUSION}

On the basis of this study, the apical sealing ability of $\mathrm{AH}$ Plus is better than tg root canal sealer in the presence and absence of smear layer. However, statistically there was no difference in the apical sealing ability among these two sealers in the presence and absence of smear layer.

\section{RECOMMENDATION}

Resin based sealers should be used in endodontic procedures to achieve a near hermetic seal. Further studies and trials especially in vivo, with different materials and methods are needed to evaluate clearly the role of smear layer in bonding and sealing.

\section{REFERENCES}

1. Cohen's pathways of the pulp. 10th ed. St. Louis, MO: Mosby; 2010.

2. S, Stanley HR, Fitzgerald RJ. The effects of surgical exposures of dental pulps in germ-free and conventional laboratory rats. Oral Surg Oral Med Oral Pathol 1965;20:340-49.

3. Gesi A, Raffaelli O, Goracci C, Pashley DH, Tay FR, Ferrari M. Interfacial strength of Resilon and gutta-percha to intraradicular dentin. J Endod 2005;31(11):809-13.

4. American Association of Endodontists. Glossary Contemporary Terminology for Endodontics, 6th Edition. American Association of Endodontists, Chicago III, USA. 1998.

5. Manjunatha M, Kini A, Sudhakar V, Sunil K V C, Hiremath V K, Shah A. Smear Layer Evaluation on Root Canal Preparation with Manual and Rotary Techniques using EDTA as an Irrigant: A Scanning Electron Microscopy Study. J Int Oral Health 2013; 5(1):66-78.

6. Torabinejad M, Handysides $R$, Khademi A, Bakland LK. Clinical implications of smear layer in endodontics: A review. Oral Radiol Endod. 2002;94:658-66.

7. Shahravan A, Haghdoost AA, Adl A, Rahimi H, Shadifar F. Effect of smear layer on sealing ability of canal obturation: a systemic review and meta analysis. J Endodon 2007; 33:96-105.

8. Galvan DA. Charlone AE. Pashley DH. Kulild JC. Primack PD. Simpson MD. Effect of smear layer removal on the diffusion permeability of human roots. J Endodon 1994; 20: 83-86.

9. Evans JT and Simon JHS. Evaluation of the apical seal produced by injected thermoplasticized gutta percha in the absence of smear layer and root canal sealer. J Endodon 1986;12: 101-07.

10. Al-Ghamdi A and Wennberg A. Testing of sealing ability of endodontic filling materials. Endo don Dent Traumotol 1994; 10: 249-55.

11. Goldman.LB, Goldman M and Letourneau JM.. Adoptation and porosity of poly-HEMA in a model system using two microorganisms. J Endodon.1980; 6: 683-86.

12. Goldberg F, Bernat M, Spielberg C, Massone EJ and Piovano SA. Analysis of the effect of ethylenediaminetetraacetic acidon the apical seal of root canal fillings. J Endodon 1985; 11:544-47

13. Matloff IR, Jensen JR, Singer L, Tabibi A. A comparison of methods used in root canal sealability studies. Oral Surg.Oral Med.Oral Pathol. 1982 Feb;53(2):203-208.

14. Jacobson SM and von Fraunhofer JA. The investigation of microleakage in root canal therapy. Oral Surg Oral Med Oral Path 1976; 42: 817-23. 
15. Ainley JE. Fluorometric assay of the apical seal of root canal fillings. Oral Surg Oral Med Oral Path 1970; 29: 753-62

16. Hovland EJ and Dumsha TC. Leakage evaluation in vitro of the root canal sealer cement Sealapex. Int Endondon J 1985;18: 179-182.

17. Wu MK, Gee AJD and Moorer WR. Fluid transport model and bacterial penetration along root canal fillings. Int Endodon J 1993; 26: 203-08.

18. Limkangwalmongkol S, Burstcher $P$, Abbott $P$, Sandler AB, Dent HD, and Bishop BM. A comparative study of the apical leakage of four root canal sealers and laterally condensed gutta percha. $J$ Endodon 1991; 17: 495-99.

19. Gee AJD, Wu MK and Wesselink PR. Sealing properties of Ketac-endo glass ionomer cement and AH26 root canal sealers. Int Endodon J 1994; 27: 239-44.

20. Osins BA, Carter JM and Shih-Levine M. Microleakage by four root canal sealers cements as determined by an electrochemical technique. Oral Surg Oral Med Oral Path. 1983; 56: 80-88.

21. Schuurs AH, Wu MK, Wesselink PR, Duivenvoorden HJ. Endodontic leakage studies reconsidered. Part II. Statistical aspects. Int.Endod.J. 1993 Jan;26(1):44-52.

22. Karagoz-Kucukay I, Bayirli G. An apical leakage study in the presence and absence of the smear layer. Int Endod J 1994;27:87-93.

23. Economides N, Liolios E, Kolokuris I, Beltes $P$. Long-term evaluation of the influence of smear layer removal on the sealing ability of different sealers. J Endod 1999;25:123-5.

24. Cobankara FK, Adanr N, Belli S. Evaluation of the influence of smear layer on the apical and coronal sealing ability of two sealers. J Endod 2004;30:406-9.

25. Torabinejad $M$, Handysides $R$, Khademi AA, Bakland LK. Clinical implications of the smear layer in endodontics: a review. Oral Surg Oral Med Oral Pathol Oral Radiol Endod 2002;94:658-66.

26. Rhode TR, Bramwell D, Hutter JW, and Roahen JO. An in vitro evaluation of microleakage of a new root canal sealer. J Endodon.1996;22:365-68.

27. Dalat DM and Onal B. Apical leakage of a glass ionomer root canal sealer. J Endodon, 1998;24:16163.

28. Kytridou V, Gutmann JL, Nunn MH. Adaptation and sealability of two contemporary obturation techniques in the absence of the dentinal smear layer. Int Endod J.1999;32:464-74.

29. Gettleman BH, Messer HH, El Deeb ME. Adhesion of sealer cements to dentin with and without the smear layer. J Endod 1991;17:15-20.

30. Cergneux M, Ciucchi B, Dietschi JM, Holz J. The influence of the smear layer on the sealing ability of canal obturation. Int Endod J 1987;20:228-32.

31. Kim YK, Grandini S, Ames JM, Gu LS, Kim SK, Pashley DH, et al. Critical review on methacrylate resin-based root canal sealers. J Endod. 2010;36:383-99.

32. CH, Zmener O. Resin materials for root canal obturation. Dent Clin North Am. 2010;54:325-44.

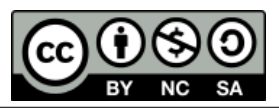

LICENSE: JGMDS publishes its articles under a Creative Commons Attribution Non-Commercial Share-Alike license (CC-BY-NC-SA 4.0). COPYRIGHTS: Authors retain the rights without any restrictions to freely download, print, share and disseminate the article for any lawful purpose. It includes scholarly networks such as Research Gate, Google Scholar, LinkedIn, Academia.edu, Twitter, and other academic or professional networking sites. 